\section{Examination of attitudes of students of sports sciences towards digital game play}

\section{Spor bilimleri fakültesi öğrencilerinin dijital oyun oynamaya yönelik tutumların incelenmesi $^{1}$}

\author{
Tuğba Mutlu Bozkurt ${ }^{2}$ \\ Mücahit Dursun ${ }^{3}$ \\ Çağrı Arri ${ }^{4}$
}

\begin{abstract}
Background and Aim: In this study, it was aimed to investigate the attitudes of students of the faculty of sports sciences to play digital games. Method: The study group consisted of a total of 141 students, $33.3 \%$ of whom were female (n: 47) and 66.7\% (n: 94) male, who were studying at Gazi University Faculty of Sport Sciences. The mean age of the students participating in the research was found to be $X_{\text {Age }}=21.69 \pm 3.08$. In order to collect data, "Personal Information Form" and "Digital Game Playing Attitude Scale" developed by Demir and Bozkurt (2019) were used. The data obtained from the study were analyzed using SPSS 22 package program. Before starting the analysis process, it was tested whether the data provided the normality assumption or not and the data supported the normality assumption. In the analysis of the data, "T-test for Independent Samples" was used for paired comparisons and "one-way ANOVA" was used for comparisons with more than two groups. Results: In the
\end{abstract}

Özet

Giriş ve Amaç: Bu araştırmada, spor bilimleri fakültesi öğrencilerinin dijital oyun oynama tutumlarının incelenmesi amaçlanmıştır. Yöntem: Araştırma grubunu, Gazi Üniversitesi Spor Bilimleri Fakültesinde öğrenim gören \%33,3’ü kadın (n: 47), \%66,7'si (n: 94) erkek olmak üzere toplamda 141 öğrenci oluşturmuş̧tur. Araştırmaya katılan öğrencilerin yaş ortalamas $X_{\text {Yas }}=21,69 \pm 3,08$ olarak tespit edilmiştir. Araştırmada veri toplamak amacıyla, Kişisel Bilgi Formu ile Demir ve Bozkurt (2019) tarafindan geliştirilen "Dijital Oyun Oynama Tutumu Ölçeğì" kullanılmıştır. Araşturmadan elde edilen veriler SPSS 22 istatistik program1 kullanılarak analiz edilmiştir. Analiz işlemine geçilmeden önce verilerin normallik varsayımını sağlayıp sağlamadığ1 sınanmıs, verilerin normallik varsayımını desteklediği görülmüsstür. Verilerin analizinde, ikili karşılaşturmalar için "Bağımsız Örneklemler için T-testi" ve ikiden fazla grubun bulunduğu karşılaştırmalarda ise "Tek Yönlü Varyans Analizi” testinden

${ }^{1} \mathrm{Bu}$ çalışma “5. International Eurasion Congress on Natural Nutrition, Healty Life and Sport, 2019, Ankara/Turkey"de sözel bildiri olarak sunulmuştur.

2 Arş. Gör., Gazi Üniversitesi, Spor Bilimleri Fakültesi, tmutlubozkurt@gmail.com Orcid ID: https://orcid.org/0000-0001-8663-2188

${ }^{3}$ Arş. Gör., Gazi Üniversitesi, Spor Bilimleri Fakültesi, mucahitdursun1903@gmail.com Orcid ID: https://orcid.org/ 0000-0002-7786-0741

4 Doktora Öğrencisi, Gazi Üniversitesi, Sağlık Bilimleri Enstitüsü, cagri.ari1989@gmail.com Orcid ID: https:/ / orcid.org/0000-0001-9910-7518 
Mutlu Bozkurt, T., Dursun, M., \& Arı, Ç. (2019). Spor bilimleri fakültesi öğrencilerinin dijital oyun oynamaya yönelik tutumlarin incelenmesi. Journal of Human Sciences, 16(4), 1217-1227. doi:10.14687/jhs.v17i1.5896

light of the findings obtained from the study, it was found that there was a statistically significant difference between the attitudes of students of sports sciences faculty towards, playing digital games, gender and duration of playing digital games and physical activity time whereas no significant difference was found according to department and class variables. Conclusion: As a result, it was found that the students' digital game playing attitudes were medium level $(X=53.95)$.

Keywords: Digital game, attitude, sports science.

(Extended English summary is at the end of this document) faydalanılmıştır. Bulgular: Araştırmadan elde edilen bulgular ışığında, spor bilimleri fakültesi ögrencilerinin dijital oyun oynamaya yönelik tutumlanyla cinsiyet, dijital oyun oynama süresi ve fiziksel aktivite süresi arasında istatistiksel olarak anlamlı farkl1lık olduğu, bölüm ve sınıf değişkenlerine göre anlamlı farklllık görülmediği anlaşılmıştır. Tartışma ve Sonuç: Sonuç olarak, öğrencilerin dijital oyun oynama tutumlarını sergileme puanlarının orta düzeyde $(X=53,95)$ olduğu tespit edilmiştir.

Anahtar Kelimeler: Dijital oyun, tutum, spor bilimleri.

\section{Giriş}

Teknoloji, internet aracillğıyla sanal bir ortamdan bilimsel bilginin sunulması, bilgiye kolaylikla ulaşılabilir olması, bilginin büyük kitlelere paylaşımın sağlanması gibi hayatı kolaylaştıran yapısı ile zaman tasarrufunu mümkün kılan bir özellikle karşımıza çıkmaktadır. Bilginin ulaşılabilirliği ve kullanılmasını sağlayan çeşitli basılmış, sesli, görsel ve yazılı araçlar bilgi ve iletişim teknolojileri kavramını gözler önüne sermiștir (Coşkun, 2015). Dijital teknoloji, bilgileri sanal olarak elektronik ortamda sergileyen, kaydeden ve ulaştıran aktiviteler olarak tanımlanırken (Cabı, 2016), dijital kelimesinin genel anlamı "var olan bir araç monitöründe sanal olarak görüntülenmesi” (TDK, 2019) olarak ifade edilmiştir. Çağımız çocukları, ergenleri ve yetişkinleri teknoloji ile birlikte yaşantı içinde olması, onların sokaktaki, parktaki oyunlar yerine sanal ortamda dijital aletler ile haşır neşir olmalarına neden olmaktadır. Bu da yetişen ve yetişmekte olan gençlerin, dijital yerliler olarak ifade edilen dijital oyun ve dijital oyun oynamaya olan ilgiyi beraberinde getirmektedir (Demir ve Bozkurt, 2019).

Teknoloji ve bilim çağında doğup yetişen günümüz gençleri, kendilerini önceki nesilden ayrıştıran, bilişsel, duyuşsal ve psikomotor olarak tercih edilen oyun ve alışkanlık bakımından farklıdırlar. Bu farklılıklar dijital oyunlardaki mantıkla aynı çerçevede yer almakta (Kula ve Erdem, 2005) ve bu durum, dijital oyun, oyuna olan ilgi ve alakanın artmas1 ve oyun oynama isteklerinde ciddi artışlara yol açmaktadır. Huizanga (2008)'nın Homo Ludens (Playing man/Oynayan insan) adlı kitabında, oyunun toplum ve sosyal hayat için öneminden bahsedilirken dijital oyunlar için ise teknoloji toplumunda dijital yerli olarak ifade edilen yeni neslin en önemli uğraşlarından birisi olduğu şeklinde yorumlanmıştır (Demir ve Hazar, 2018). Milenyum neslinin eğlenmek ve zaman geçirmek için kullandıkları araçların başında bilgisayar oyunlarının geldiğini belirten Bozkurt, (2014), dijital oyunların kişilerin oyalanma, vakit geçirme nedenleri ve dijital oyun tercihleri (Topal ve Aydın, 2018; İnal ve Çağıltay, 2005; Carr, 2005; Durdu, Tüfekçi ve Çağıltay., 2005; Lazzaro, 2004; Squire, 2003; Prensky, 2001), dijital oyun bağımlılı̆̆1 (Güvendi, Demir ve Keskin, 2019; Hazar ve Hazar, 2017; Hazar, Tekkurşun ve Dalkıran., 2017; Ekinci, Üstün ve Özer., 2016) ve dijital oyun oynama motivasyonu (Demirel, Cicioğlu ve Demir, 2019; Demir ve Hazar, 2018), en fazla tercih edilen dijital oyunlar ve çocukların gelişimine etkisi (Mustafaoğlu vd., 2018; Dursun vd., 2017; QuaiserPohl, Geiser ve Lehmann, 2006) araştırılan konular içinde yer almaktadır. 
Mutlu Bozkurt, T., Dursun, M., \& Arı, Ç. (2019). Spor bilimleri fakültesi öğrencilerinin dijital oyun oynamaya yönelik tutumların incelenmesi. Journal of Human Sciences, 16(4), 1217-1227. doi:10.14687/jhs.v17i1.5896

Tutum, bireylerin hal, tavır ve davranışlarını, sosyal ilgileri ortaya çıkaran önemli psikolojik özelliklerden olan (Alıc1, 2013) ve başka bir ifade ile kişinin bir olay, olgu ya da durum karşısında göstermesi beklenen olası tavır, davranış şeklinde ifade edilebilir (İnceoğlu, 2010). Tutumların var oluş nedeni, tutumun kişilerin tavırlarına etkisi ve bu tutumların zamana karşı koyamayarak değişmesi, bilim ve teknoloji çağında olan toplumun devamlı dikkatini çekmekte, birçok çalışmanın odak noktasında bulunmaktadır (Demir vd., 2017). Dijital oyun oynamaya olan tutum ise, bireylerin kafasını boşaltma isteği, eğlence arayışı içinde oluşu, asosyal hayat tarzından uzaklaşma isteği, çevresinden kaçma arzusu, yaşadığı hayatta ulaşamadıklarına dijital alanda uygulamak istemesi oluşturmaktadır (Demir ve Bozkurt, 2019). Tutumlar bilişsel, duyguşsal ve psikomotor olarak üç alt boyuttan meydana gelmektedir ve bu alt boyutlar birbiri içine girişken hareketli bir döndü halindedir (Tavşancıl, 2014). Bu bağlamda kişinin bir durum karşısında sergilediği bilgi o duruma olan zihinsel tavrını, kişinin olumlu hali duyguşsal tavrını, göstermiş olduğu davranışlar ise psikomotor tavrı ile tutumun alt boyutlarını oluşturur (Hazar ve Demir, 2018). Bu noktada bu araştırma ile Spor Bilimleri Fakültesi öğrencilerinin dijital oyun oynamaya yönelik tutumunun belirlenmesi amaçlanmıştur.

\section{Yöntem}

\subsection{Araştırmanın Modeli}

Spor Bilimleri Fakültesi öğrencilerinin dijital oyun oynamaya yönelik tutumlarını belirlemek amacıyla yapılan bu çalışmada, "geçmişten günümüze halen devam etmekte olan bir olgu ya da olayı olduğu gibi resmetmeyi hedefleyen ve çalşsmaya konu olan durum için, kişinin ya da nesnenin, var olduğu gibi betimlenmeye çalışıldığı" tarama modeli kullanılmıştır (Karasar, 2014).

\subsection{Araştırma Grubu}

Araştırmaya, Gazi Üniversitesi Spor Bilimleri Fakültesinde eğitimine devam eden \%66,7'si erkek ( $n=94), \% 33,3$ ü kadın ( $n=47)$ olmak üzere toplamda 141 öğrenci gönüllü olarak katılmıştır.

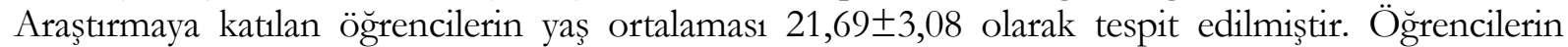
demografik özelliklerine ilişkin frekans ve yüzde dağılımları Tablo 1'de gösterilmektedir.

Tablo 1. Öğrencilerin demografik özelliklerine ilisskin frekans ve yüzde dağılımları

\begin{tabular}{|c|c|c|c|}
\hline Değişken & & f & $\%$ \\
\hline \multirow[t]{4}{*}{ Bölüm } & Antrenörlük & 39 & 27,7 \\
\hline & Beden Ë̆itimi Öğretmenlï̆i & 25 & 17,7 \\
\hline & Rekereasyon & 27 & 19,1 \\
\hline & Spor Yöneticiliğ & 50 & 35,5 \\
\hline \multirow[t]{4}{*}{ Simif } & 1. Simif & 51 & 36,2 \\
\hline & 2. Simif & 28 & 19,9 \\
\hline & 3. Sinif & 35 & 24,8 \\
\hline & 4. Simef & 27 & 19,1 \\
\hline Dijital Oyun Oynama & $30-60 d k$ & 75 & 53,2 \\
\hline \multirow[t]{3}{*}{ Süresi } & $61-90 \mathrm{dk}$ & 32 & 22,7 \\
\hline & $91-120 \mathrm{dk}$ & 21 & 14,9 \\
\hline & 121 ve üzeri & 13 & 9,2 \\
\hline \multirow[t]{4}{*}{ Fiqilksel Aktivite Süresi } & $30-60 d k$ & 43 & 30,5 \\
\hline & $61-90 \mathrm{dk}$ & 34 & 24,1 \\
\hline & $91-120 d k$ & 26 & 18,4 \\
\hline & 121 ve üzeri & 38 & 27,0 \\
\hline Toplam & & 141 & 100,0 \\
\hline
\end{tabular}


Mutlu Bozkurt, T., Dursun, M., \& Arı, Ç. (2019). Spor bilimleri fakültesi öğrencilerinin dijital oyun oynamaya yönelik tutumlarin incelenmesi. Journal of Human Sciences, 16(4), 1217-1227. doi:10.14687/jhs.v17i1.5896

\subsection{Veri Toplama Araçları}

Kişisel Bilgi Formu: Araştırmacılar tarafindan hazırlanan "Kişisel Bilgi Formu", araştırmaya katılan öğrencilerin demografik özellikleri (cinsiyet, yaş, bölüm, sınıf, dijital oyun oynama süresi, fiziksel aktivite süresi) hakkında veri toplamak amacıyla oluşturulmuştur.

Dïjital Oyun Oynama Tutumu Ölçeği (DOOTÖ): Demir ve Bozkurt (2019) tarafindan geliştirilen "Dijital Oyun Oynama Tutumu Ölçeği"; "Bilişsel”"(5 madde), "Duyuşsal"(5 madde) ve "Davranışsal"'(8 madde) olmak üzere toplam 3 alt boyut ve 18 maddeden oluşmaktadır. Ölçek, "Hiç katılmiyorum" (1) ifadesinden "Tamamen katılıyorum"(5) ifadesine doğru 5'li Likert tipinde derecelendirilmiştir. Ölçekten alınabilecek en düşük puan 18, en yüksek puan 90'dır. DOOTÖ'nün 2., 3., 5., 6., 7., 10. ve 18. maddeleri ters kodlanmıştır. Ölçeğin güvenirliğine ilişkin iç tutarlılık katsayısı, "Bilişsel Alt Boyut" için .90, "Duyuşsal Alt Boyut" için .81 ve "Davranışsal Alt Boyut" için .91 olarak tespit edilmiştir. Ölçeğin bütünü için iç tutarlılık katsayısı .82'dir. Bu çalışmada ise, ölçeğin bütününe ilişkin iç tutarllık katsayıs1 .88, "Bilişsel Alt Boyut" için .65, "Duyuşsal Alt Boyut" için .69 ve "Davranışsal Alt Boyut" için ise .86'dır.

Tablo 2. Dijital Oyun Oynama Tutumu Ölçeğine İlişkin Güvenirlik Katsayıları

\begin{tabular}{|c|c|c|}
\hline $\begin{array}{l}\text { Dijital Oyun Oynama Tutumu } \\
\text { Ölçeği }\end{array}$ & $\begin{array}{c}\text { Chronbach's Alpha ( } \\
\alpha)\end{array}$ & Madde Sayısı \\
\hline Bilişsel Boyut & .65 & 5 \\
\hline Duyuşsal Boyut & .69 & 5 \\
\hline Davranışsal Boyut & .86 & 8 \\
\hline DOOTÖ Toplam & .88 & 18 \\
\hline
\end{tabular}

Özdamar (1999)'a göre güvenirlik katsayısına ilişkin ölçüt değerleri;

$0.00<\alpha<0,40$ olduğu zaman "güvenilir değil",

$41<\alpha<0,60$ olduğu zaman "düşük güvenirlikte".

$0,61<\alpha<0,80$ olduğu zaman "orta düzeyde güvenilir".

$0,81<\alpha<1,00$ olduğu zaman "yüksek düzeyde güvenilir"

Alanyazın ölçütlerine göre toplanan verilerin güvenirlik için yeterli seviyelerde olduğu Tablo 2. incelendiğinde görülmektedir.

\subsection{Verilerin Analizi}

Araştırma kapsamında elde edilen verilerin analizine geçmeden önce, verilerin normal dağılım gösterip göstermediği çarpıklık (skewness) ve basıklık (kurtosis) katsayıları incelenerek belirlenmiştir. Çarpıklık ve basıklık katsayıları incelendiğinde, Tabachnick ve Fidel (2015)'in belirttiği sınırlar içerisinde (-1.5 ile +1.5$)$ yer alan veri setinin normal bir dağıllıma sahip olduğu görülmektedir (Tablo 3). Verilerin normallik varsayımını sağlayıp sağlamadığını belirlemenin bir diğer yolu da ortalama, mod ve medyan değerlerini incelemektir. Literatürde, "verilerin ortalama, mod ve medyan değerlerinin birbirine yakınlığının verilerin normal dağılım gösterdiği şeklinde yorumlanabileceğı" görüşü normallik varsayımı olarak değerlendirilmiştir (Büyüköztürk, Köklü ve Çokluk Bökeoğlu, 2006). Değerler ve referanslar göz önünde bulundurulduğunda; veri setinin parametrik testlere uygun bir yapıda olduğu görülmüştür. Bu bağlamda, ikili karşılaştırmalar için Bağımsız Örneklemler için T-Testi, ikiden fazla grubun bulunduğu karşılaştırmalarda ise Tek Yönlü Varyans Analizi kullanılmıştır. Varyans analizi sonuçlarının anlamlı çıkması halinde, farklılı̆̆ın hangi gruplar arasında oluştuğunu belirlemek amacıyla Tukey HSD çoklu karşılaştırma testinden faydalanılmıştır. Araştırma grubunu oluşturan öğrencilerin demografik özelliklerinin belirlenmesinde ise frekans (f), yüzde (\%), ortalama (X) ve standart sapma (ss) gibi betimsel istatistik yöntemleri kullanılmıştır. Veriler SPSS 22 istatistik programı kullanılarak analiz edilmiştir. 
Mutlu Bozkurt, T., Dursun, M., \& Arı, Ç. (2019). Spor bilimleri fakültesi öğrencilerinin dijital oyun oynamaya yönelik tutumların incelenmesi. Journal of Human Sciences, 16(4), 1217-1227. doi:10.14687/jhs.v17i1.5896

Tablo 3. DOOT Ölçeğinin Alt Boyutlarına İlişkin Betimsel Analiz

\begin{tabular}{cccccccccc}
\hline Alt Boyut & n & Min. & Max. & $\mathbf{X}$ & Ss & mod & $\begin{array}{c}\text { medya } \\
\mathbf{n}\end{array}$ & $\begin{array}{c}\text { skewnes } \\
\text { s }\end{array}$ & $\begin{array}{c}\text { kurtos } \\
\text { is }\end{array}$ \\
\hline Bilisssel Boyut & 141 & 5,00 & 25,00 & 14,51 & 4,48 & 15,00 & 14,00 &, 450 &,- 044 \\
\hline Duyussal Boyut & 141 & 5,00 & 25,00 & 15,77 & 4,44 & 15,00 & 16,00 &,- 159 &,- 240 \\
\hline Davramıssal Boyut & 141 & 8,00 & 40,00 & 23,67 & 8,05 & 24,00 & 23,00 &, 167 &,- 531 \\
\hline DOОТÖ & 141 & 18,00 & 90,00 & 53,95 & 14,48 & 50,00 & 53,00 &, 181 &, 098 \\
\hline
\end{tabular}

Dijital Oyun Oynama Tutumu Ölçeği alt boyutlarının genel ortalamalarına bakıldığında, en yüksek ortalamanın "davranışsal tutum" alt boyutunda $(X=23,67 \pm 8,05)$, en düşük ortalama değerin

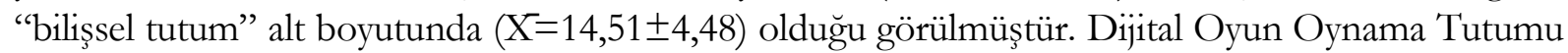
Ölçeği toplam puan ortalaması ise $(X=53,95 \pm 14,48)$ olarak tespit edilmiştir.

\section{Bulgular}

$\mathrm{Bu}$ bölümde veri toplama aracının (Dijital Oyun Oynama Tutumu Ölçeği) uygulanması sonucunda elde edilen verilerin istatistiksel analizleri ve yorumları bulunmaktadır.

Tablo 4. Öğrencilerin Dijital Oyun Oynama Tutum Ölçeği Puanlarının Cinsiyet Değişkenine Göre Farklıllğı için T-testi Sonuçları

\begin{tabular}{cccccccc}
\hline Ölçek & $\begin{array}{c}\text { Cinsiye } \\
\mathbf{t}\end{array}$ & $\mathbf{n}$ & $\mathbf{X}$ & Ss & sd & $\mathbf{t}$ & $\mathbf{p}$ \\
\hline Bilissel Boyut & Kadm & 47 & 13,19 & 4,71 & 139 & $-2,515$ &, $\mathbf{0 1 3}$ \\
& Erkek & 94 & 15,17 & 4,24 & & & \\
\hline Duyussal Boyut & Kadm & 47 & 13,93 & 4,92 & 139 & $-3,349$ &, $\mathbf{0 0 1}$ \\
& Erkek & 94 & 16,69 & 3,89 & & & \\
\hline Davranıssal Boyut & Kadm & 47 & 21,78 & 9,23 & 139 & $-1,836$ &, 070 \\
& Erkek & 94 & 24,61 & 7,26 & & & \\
\hline
\end{tabular}

Tablo 4 incelendiğinde öğrencilerin cinsiyet değişkeni ile DOOTÖ alt boyutları arasındaki Ttesti sonuçları verilmiştir. Buna göre, öğrencilerin dijital oyun oynama tutumları cinsiyet değisskenine göre "Bilişsel" ve "Duyuşsal" alt boyutlarında anlamlı bir farklılık göstermiştir $(p<0,05)$. Davranışsal alt boyutunda ise cinsiyet değişkenine göre anlamlı bir farkllık tespit edilmemiştir. Erkek öğrencilerin kadın öğrencilere göre dijital oyun oynama tutumlarının daha yüksek olduğu görülmüştür.

Tablo 5. Öğrencilerin Dijital Oyun Oynama Tutum Ölçeği Puanlarının Bölüm Değişkenine Göre Farklıllı̆ı için Tek Yönlü Varyans Analizi Sonuçları

\begin{tabular}{cccccccc}
\hline Ölçek & Sinıf & n & X & s & f & p & Tukey \\
\hline Bilissel & Antrenörlïk $^{1}$ & 39 & 15,05 & 4,32 &, 274 &, 844 & - \\
Boyut & Öretmenlik $^{2}$ & 25 & 14,40 & 5,09 & & & \\
& Rekreasyon $^{3}$ & 27 & 14,40 & 3,41 & & & \\
& Yöneticilik $^{4}$ & 50 & 14,20 & 4,87 & & & \\
\hline
\end{tabular}


Mutlu Bozkurt, T., Dursun, M., \& Arı, Ç. (2019). Spor bilimleri fakültesi öğrencilerinin dijital oyun oynamaya yönelik tutumların incelenmesi. Journal of Human Sciences, 16(4), 1217-1227. doi:10.14687/jhs.v17i1.5896

\begin{tabular}{|c|c|c|c|c|c|c|c|}
\hline \multirow{4}{*}{$\begin{array}{c}\text { Duyussal } \\
\text { Boyut }\end{array}$} & Antrenörlïk. & 39 & 16,41 & 3,83 & \multirow[t]{4}{*}{,836 } & \multirow[t]{4}{*}{,476 } & \multirow[t]{4}{*}{ - } \\
\hline & Ögrretmenlike ${ }^{2}$ & 25 & 15,80 & 5,33 & & & \\
\hline & Rekreasyon ${ }^{3}$ & 27 & 16,22 & 3,26 & & & \\
\hline & Yöneticilike & 50 & 15,02 & 4,93 & & & \\
\hline \multirow{4}{*}{$\begin{array}{c}\text { Davramissal } \\
\text { Boyut }\end{array}$} & Antrenörlïk ${ }^{1}$ & 39 & 25,00 & 7,15 & \multirow[t]{4}{*}{, 501} & \multirow[t]{4}{*}{ 682 } & \multirow[t]{4}{*}{-} \\
\hline & Ögretmenlik ${ }^{2}$ & 25 & 23,44 & 8,61 & & & \\
\hline & Rekreasyon ${ }^{3}$ & 27 & 23,25 & 7,36 & & & \\
\hline & Yöneticilike & 50 & 22,98 & 8,86 & & & \\
\hline
\end{tabular}

Tablo 5 incelendiğinde öğrencilerin bölüm değişkeni ile DOOTÖ alt boyutları arasındaki tek yönlü varyans analizi sonuçları verilmiştir. Buna göre, öğrencilerin dijital oyun oynama tutumları bölüm değişkenine göre anlamlı bir şekilde farklılaşmamaktadır.

Tablo 6. Öğrencilerin Dijital Oyun Oynama Tutum Ölçeği Puanlarının Sınıf Değişkenine Göre Farkllı̆ı̆ı için Tek Yönlü Varyans Analizi Sonuçları

\begin{tabular}{|c|c|c|c|c|c|c|c|}
\hline Ölçek & Sinif & $\mathrm{n}$ & $\mathrm{X}$ & $\mathbf{s}$ & f & $\mathrm{p}$ & Tukey \\
\hline Bilisssel & 1. Simef & 51 & 13,72 & 4,94 & 1,988 & 119 & - \\
\hline \multirow[t]{3}{*}{ Boyut } & 2. Simif & 28 & 16,25 & 4,02 & & & \\
\hline & 3. Simf & 35 & 14,31 & 4,61 & & & \\
\hline & 4. Simif & 27 & 14,44 & 3,48 & & & \\
\hline Duyussal & 1. Sinrf & 51 & 15,13 & 5,09 & 843, & 473, & - \\
\hline \multirow[t]{3}{*}{ Boyut } & 2. Simif & 28 & 16,75 & 4,50 & & & \\
\hline & 3. Simif & 35 & 15,68 & 3,92 & & & \\
\hline & 4. Simif & 27 & 16,07 & 3,63 & & & \\
\hline Davramısssal & 1. Simef & 51 & 23,00 & 9,09 & ,400 & ,753 & - \\
\hline \multirow[t]{3}{*}{ Boyut } & 2. Simif & 28 & 23,96 & 7,85 & & & \\
\hline & 3. Simes & 35 & 23,37 & 7,14 & & & \\
\hline & 4. Simeft & 27 & 25,03 & 7,50 & & & \\
\hline
\end{tabular}

Tablo 6 incelendiğinde öğrencilerin sınıf değişkeni ile DOOTÖ alt boyutları arasındaki tek yönlü varyans analizi sonuçları verilmiştir. Buna göre, öğrencilerin dijital oyun oynama tutumları sınıf değişkenine göre anlamlı bir şekilde farklılaşmamaktadır.

Tablo 7. Öğrencilerin Dijital Oyun Oynama Tutum Ölçeği Puanlarının Dijital Oyun Oynama Süresi Değisskenine Göre Farklıllğı için Tek Yönlü Varyans Analizi Sonuçları

\begin{tabular}{|c|c|c|c|c|c|c|c|}
\hline Ölçek & $\begin{array}{c}\text { Dijital Oyun } \\
\text { Oynama Süresi }\end{array}$ & $\mathbf{n}$ & $\mathbf{X}$ & $\mathbf{s}$ & f & $\mathrm{p}$ & $\begin{array}{c}\text { Tuke } \\
\mathbf{y}\end{array}$ \\
\hline \multirow[t]{4}{*}{ Bilissel Boyut } & $30-60 d k^{1}$ & 75 & 13,70 & 4,25 & 7,826 &, 000 & $4>1$ \\
\hline & $61-90 d k^{2}$ & 32 & 13,68 & 3,29 & & & $4>2$ \\
\hline & $91-120 d k^{3}$ & 21 & 15,57 & 4,83 & & & $4>3$ \\
\hline & 121 ve üzern ${ }^{4}$ & 13 & 19,46 & 4,68 & & & \\
\hline \multirow[t]{4}{*}{ Duyussal Boyut } & $30-60 d k^{1}$ & 75 & 13,90 & 3,97 & 18,036 & ,000 & $2>1$ \\
\hline & $61-90 d k^{2}$ & 32 & 16,15 & 3,93 & & & $3>1$ \\
\hline & $91-120 d k^{3}$ & 21 & 18,71 & 3,31 & & & $4>1$ \\
\hline & 121 ve üzert & 13 & 20,84 & 3,07 & & & $4>2$ \\
\hline
\end{tabular}


Mutlu Bozkurt, T., Dursun, M., \& Arı, Ç. (2019). Spor bilimleri fakültesi öğrencilerinin dijital oyun oynamaya yönelik tutumların incelenmesi. Journal of Human Sciences, 16(4), 1217-1227. doi:10.14687/jhs.v17i1.5896

\begin{tabular}{llllllll}
\hline Davranıssal Boyut & $30-60 \mathrm{dk}^{1}$ & 75 & 20,73 & 7,25 & 9,819 & $\mathbf{0 0 0}$ & $2>1$ \\
& $61-90 \mathrm{dk}^{2}$ & 32 & 25,15 & 7,70 & & & $3>1$ \\
& $91-120 \mathrm{dk}^{3}$ & 21 & 28,38 & 6,93 & & & $4>1$ \\
& 121 ve üzern $^{4}$ & 13 & 29,38 & 8,10 & & & \\
\hline
\end{tabular}

Tablo 7 incelendiğinde öğrencilerin dijital oyun oynama süresi değişkeni ile DOOTÖ alt boyutları arasındaki tek yönlü varyans analizi sonuçları verilmiştir. Buna göre, öğrencilerin dijital oyun oynama tutumları dijital oyun oynama süresi değişkenine göre "Bilişsel", "Duyuşsal" ve "Davranışsal" alt boyutlarında anlamlı bir farklılık göstermiştir. Tukey testi sonuçlanına göre tüm alt boyutlarda gruplar arası farklilı̆ın, "30-60 dk", "61-90 dk", “91-120 dk" ve "120 ve üzeri” gruplar1 arasında "121 ve üzeri”" grubu lehine gerçekleştiği belirlenmiştir. Bu sonuca göre, dijital oyun oynama süresi arttıkça dijital oyun oynama tutumunda da artış gözlemlenmektedir.

Tablo 8. Öğrencilerin Dijital Oyun Oynama Tutum Ölçeği Puanlarının Fiziksel Aktivite Süresi Değişkenine Göre Farklılı̆̆ için Tek Yönlü Varyans Analizi Sonuçları

\begin{tabular}{|c|c|c|c|c|c|c|c|}
\hline Ölçek & $\begin{array}{c}\text { Fiziksel Aktivite } \\
\text { Süresi }\end{array}$ & n & $\mathbf{X}$ & $\mathbf{s}$ & $f$ & $\mathrm{p}$ & Tukey \\
\hline \multirow[t]{4}{*}{ Bilissel Boyut } & $30-60 d k^{1}$ & 43 & 13,79 & 3,93 & 2,533 & ,060 & - \\
\hline & $61-90 d k^{2}$ & 34 & 14,64 & 4,69 & & & \\
\hline & $91-120 d k^{3}$ & 26 & 16,53 & 5,43 & & & \\
\hline & 121 ve üzert & 38 & 13,81 & 3,87 & & & \\
\hline \multirow[t]{4}{*}{ Duyussal Boyut } & $30-60 d k^{1}$ & 43 & 15,76 & 4,21 & 2,235 & ,087 & - \\
\hline & $61-90 d k^{2}$ & 34 & 14,73 & 4,85 & & & \\
\hline & $91-120 d k^{3}$ & 26 & 17,61 & 4,45 & & & \\
\hline & 121 ve üzert ${ }^{4}$ & 38 & 15,44 & 4,07 & & & \\
\hline Davranışsal & $30-60 d k^{1}$ & 43 & 22,09 & 7,23 & 5,276 & ,002 & $3>1$ \\
\hline \multirow[t]{3}{*}{ Boyut } & $61-90 d k^{2}$ & 34 & 23,73 & 8,11 & & & $3>4$ \\
\hline & $91-120 d k^{3}$ & 26 & 28,88 & 6,90 & & & \\
\hline & 121 ve üzern ${ }^{4}$ & 38 & 21,84 & 8,35 & & & \\
\hline
\end{tabular}

Tablo 8 incelendiğinde öğrencilerin fiziksel aktivite süresi değişkeni ile DOOTÖ alt boyutlan arasındaki tek yönlü varyans analizi sonuçları verilmiştir. Buna göre, öğrencilerin dijital oyun oynama tutumları fiziksel aktivite süresi değişkenine göre "Davranışsal" alt boyutunda anlamlı bir farklılık göstermiştir. Bilişsel ve Duyuşsal alt boyutlarında ise fiziksel aktivite süresi değişkenine göre anlamlı bir farklılık tespit edilememiştir. Tukey testi sonuçlarına göre gruplar arası farklılı̆ın, "30-60 $\mathrm{dk}$ " ve "91-120 dk" gruplar1 arasinda "91-120 dk" grubu lehine, "91-120 dk" ve "121 ve üzeri" grupları arasında ise "91-120 dk" grubu lehine gerçekleștiği belirlenmiştir.

\section{Tartışma ve Sonuç}

Günümüz dünyasında gençlerinin dijital oyun oynama isteği, gerek sosyal çevrelerinden uzaklaşmak gerekse de eğlenmek amacı içinde oluşu dijital oyun oynama tutumunu etkilediği düşünülmektedir (Demir ve Bozkurt, 2019). Bu durum göz önüne alınarak, araştırmada Spor Bilimleri Fakültesi öğrencilerinin dijital oyun oynama tutumlarını tespit etmek amaçlanmıştır. Çalışmaya Gazi Üniversitesi Spor Bilimleri Fakültesinde öğrenim gören lisans düzeyindeki Beden Eğitimi ve Spor Öğretmenliği bölümünden 25, Antrenörlükten 39, Spor Yöneticiliğinden 50 ve Rekreasyondan 27 olmak üzere 141 öğrenci katılmıştır. Literatürde aynı çalışma ile ilgili yapılan çalışmaya rastlanmamıştır. Ancak dijital oyun, teknoloji ve tutumun farklı çalışmalarda ayrı ayrı değinen kaynaklar yol gösterici nitelik taşımışır. 
Mutlu Bozkurt, T., Dursun, M., \& Arı, Ç. (2019). Spor bilimleri fakültesi öğrencilerinin dijital oyun oynamaya yönelik tutumların incelenmesi. Journal of Human Sciences, 16(4), 1217-1227. doi:10.14687/jhs.v17i1.5896

Araştırmanın ilk bulgusunda dijital oyun oynama tutumu alt boyutlarından "Bilişsel” ve "Duyuşsal" ile cinsiyet değişkeni arasında anlamlı bir farklılık tespit edilmiştir. Bilişsel ve duyuşsal alt boyutta erkek öğrencilerin kadın öğrencilere göre dijital oyun oynama tutumlarının daha yüksek olduğu görülmüştür. Diğer bir deyişle kadın öğrencilerin dijital oyun oynama tutumlarının düşük olması daha duygusal olmaları ve sosyal çevre ile daha yakından iletişim halinde olmaları gösterilebilir. Ayrıca erkek öğrencilerin dijital oyun oynama tutumlarının, kupa kazanma, mücadele etme, dövüş teknikleri ile yakından ilgilenme, futbol gibi branşların dijital ortamda istenilen zaman ve mekan da reel rakibe ihtiyaç duymadan oynayabilmeleri, mutluluk, hırs, başarma arzularını artırdığ söylenebilir. Media Analysis Laboratory (1998) tarafından yapılan araştırmada erkeklerin oyunlara daha fazla zaman ayırdıkları ve tercih edilen oyunların erkeklerin daha fazla ilgi duydukları alanlar olan macera, dövüş, yarış ve spor olduğu, tespit edilmiştir. Başka bir araştırmada ise oyunların erkeklerin ilgi alanında olması kadınların dijital oyun oynama tutumunu düşürmekte ve erkeklerin kadınlara göre daha çok oyun oynamaya yönlendiren nedenler olarak belirtilmektedir (Balıkç1, 2018; Quaiser-Pohl, Geiser ve Lehmann, 2006; Griffiths ve Davies, 2005). Literatürde benzer sonuca ulaşan diğer bir çalışma ise Sherry, Holmstrom, Binns, Greenberg and Lachlan'ın (2003) bulgusunda erkeklerin kadınlara oranla daha çok dijital oyun oynadıkları yönünde farklılıklar olduğunu göstermekle birlikte benzer sonuçlara ulaşan Yengin (2012); Pala ve Erdem (2011) ve Lucas ve Sherry (2004) çalışmalar da mevcuttur.

Araştırmanın ikinci bulgusunda öğrencilerin dijital oyun oynama tutumları ile bölüm değişkeni arasında anlamlı bir farklılık bulunmamıştır. Aynı üniversite de aynı fakülte de farklı bölümlerde öğrenim gören öğrencilerinin almış oldukları ortak eğitim müfredatı ve paylaşılan sosyal çevrelerinin ortak olması dijital oyun oynama tutumlarında fark olmamasına etki ettiği düşünülmektedir. Çakır, Ayas ve Horzum, (2011) yaptıkları araşturmada öğrenimlerine devam eden üniversite öğrencilerin öğrenim düzeylerine göre bilgisayar oyun bağımlılı̆̆1 ve internet bağımlılığ1 açısından anlamlı bir farklılık bulunmadığı sonucuna ulaşılmıştır.

Araştırmanın üçüncü bulgusunda öğrencilerin dijital oyun oynama tutumları ile sınıf değisskeni arasında anlamlı bir farklılık tespit edilmemiştir. 1.2.3. ve 4. Sınıf üniversite öğrencilerinin farklı yaş gruplarında olmalarına rağmen aynı ortamın, aynı çevrenin, aynı neslin gençleri olmaları, öğrencilerin dijital oyun oynama tutumlarını da etkilediği söylenebilir. Marshall ve Foran, (2008)'1n 18-35 yaş aralığında sınıf düzeylerine göre katılımcıların oyun tercihlerinde anlamlı bir farklılık bulunmamıştır, bulgularımızı destekleyen çalışmalar (Demirel, Cicioğlu ve Demir, 2019; İnal ve Çağıltay, 2005) yer almaktadır. Araştırmamızdan farklı olarak Buchman ve Funk (1996), farklı sınıf düzeylerindeki kız ve erkek öğrencilerin dijital oyun oynama tercihlerini araştırmış ve eğitim seviyesi artan öğrencilerin eğitim içeriğine sahip oyun oynama seviyesinin azaldı̆̆ını belirtmiştir.

Araştırmanın dördüncü bulgusunda öğrencilerin dijital oyun oynama tutumları ile dijital oyun oynama süresi değişkeni arasında "Bilişsel", "Duyuşsal" ve "Davranışsal" alt boyutlarında anlamlı farklılık bulunmuştur. Dijital oyun oynama tutum ölçeği tüm alt boyutlarda gruplar arası farklılığın, “30-60 dk", “61-90 dk", “91-120 dk" ve "120 ve üzeri” gruplar1 arasında "121 ve üzeri” grubu lehine gerçekleştiği belirlenmiştir. Bu sonuca göre, dijital oyun oynama süresi arttıkça dijital oyun oynama tutumunda da artış olduğu söylenebilir. Mustafaoğlu ve Yasac1, (2018)'de yaptı̆1 araştırmada ortaokuldaki öğrencilerin ilkokulda ki öğrencilere göre bir gün içinde aktif olarak daha uzun süre dijital oyun oynadıkları saptanmış olup artan yaşla birlikte dijital oyun oynama tutumunun da artacağı ifade edilebilir. Başka bir çalışmada ise katılımcıların günlük dijital oyun oynama süreleri arttıkça fiziksel aktiviteye katılım motivasyonu düşmekte olduğu sonucuna varılmıştır ( Demir ve Cicioğlu, 2019).

Araştırmanın son bulgusunda öğrencilerin dijital oyun oynama tutumları ile fiziksel aktivite süresi değişkeni arasında "Davranışsal" alt boyutunda anlamlı bir farklılık saptanmıştır. Bilişsel ve Duyuşsal alt boyutlarında ise fiziksel aktivite süresi değişkenine göre anlamlı bir farklılık tespit edilmemiştir. Fiziksel aktive süresi “30-60 dk" ve "91-120 dk" gruplar1 arasinda "91-120 dk" grubu lehine, "91-120 dk" ve "121 ve üzeri" grupları arasında ise "91-120 dk" grubu lehine gerçekleştiği belirlenmiştir. Buna bağlı olarak fiziksel aktivite süresi arttıkça dijital oyun oynamaya yönelik 
Mutlu Bozkurt, T., Dursun, M., \& Arı, Ç. (2019). Spor bilimleri fakültesi öğrencilerinin dijital oyun oynamaya yönelik tutumların incelenmesi. Journal of Human Sciences, 16(4), 1217-1227. doi:10.14687/jhs.v17i1.5896

tutumlarının da arttı̆̆ı söylenebilir. Elde edilen bu sonuca göre fiziksel aktivite içinde yer alan enerji boşaltma ihtiyacı gibi olguların dijital oyunlardaki heyecan, yarışma, hırs ile aynı kabul edilmesinden kaynaklandığ1 düşünülebilir. Literatürde fiziksel aktiviteye katılanların dijital oyun oynama motivasyonlarının düşük olduğunu tespit eden araştırmalarla (Demirel, Cicioğlu ve Demir, 2019; Demir ve Cicioğlu, 2018; Biddiss ve Irwin, 2010) farkl1llk gösterdiği söylenebilir.

Sonuç olarak, spor bilimleri fakültesi öğrencilerinin dijital oyun oynamaya yönelik tutumlarıyla cinsiyet, dijital oyun oynama süresi ve fiziksel aktivite süresi arasında istatistiksel olarak anlamlı farklılık olduğu, bölüm ve sınıf değişkenlerine göre anlamlı farklılık görülmediği anlaşılmıştır. Sonuç olarak, öğrencilerin dijital oyun oynama tutumlarını sergileme puanlarının orta düzeyde $(X=53,95)$ olduğu tespit edilmiştir.

\section{Kaynakça}

Alıcı, D. (2013), Okula Yönelik Tutum Ölçeğinin Geliştirilmesi: Güvenirlik Ve Geçerlik Çalışması. Ë̈itim ve Bilim, 38(168), 318-331.

Balıkçı, R. (2018). Cocuklarda ve Ergenlerde Cevrimiçi Oyun Băğmllhŭg Ve Agresif Davramșlar Arasındaki İlişkinin Incelenmesi. Yüksek Lisans Tezi. Fatih Sultan Mehmet Vakıf Üniversitesi Sosyal Bilimler Enstitüsü, İstanbul.

Biddiss, E. ve Irwin, J. (2010). Active Video Games to Promote Physical Activity in Children and Youth. Arch Pediatr Adolesc Med, 164:664-672.

Buchman, D. D. ve Funk, J. B. (1996). Video and computer games in the, 90s: Children time commitment ve game preferences. Children Today, 24 (1). Database: Academic Search Premier.

Büyüköztürk, S.., Köklü, N. ve Çokluk-Bökeoğlu, Ö. (2006). Sosyal Bilimleri için İstatistik, 2. Baskı. Ankara: Pegem A Yayıncilik.

Bozkurt, A. (2014). Homo Ludens: Dijital oyunlar ve eğitim. Eğitim Teknolojileri Arașttrmalar Dergisi, 5(1).

Cabı, E. (2016). Dijital teknolojiye yönelik tutum ölçeği. Kastamonu Eğitim Dergisi, 24(3), 1229-1244.

Carr, D. (2005), Contexts, Pleasures and Preferences: Girls playing computer games. In: Changing Viens: Worlds in Play. Selected papers of the 2005 Digital Games Research Assoc. 2nd International Conference. Digital Games Research Association, 313-322.

Çakır, Ö, Ayas, T. ve Horzum, M.B. (2011). Üniversite Öğrencilerinin İnternet ve Oyun Bağımlılıklarının Çeşitli Değişkenlere Göre İncelenmesi. Ankara Üniversitesi Eğitim Bilimleri Fakültesi Dergisi, 44( 2), 95-117.

Çoşkun B., (2015). İletişim teknolojilerinin stratejik kaynak yönetimi: Türk Telekomünikasyon Anonim Şirketi (ttaş) örneği, Uluslararası İktisadi ve İdari Bilimler Dergisi, 1 (1) 2015, 31-53.

Demir, G. T., ve Cicioğlu, H. İ. (2019). Fiziksel Aktiviteye Katılım Motivasyonu İle Dijital Oyun Oynama Motivasyonu Arasındaki İlişkinin İncelenmesi. Spormetre Beden Eğitimi Ve Spor Bilimleri Dergisi, 17(3), 23-34.

Demir, G. T, Cicioğlu, H. İ, İlhan, E. L. ve Arslan, Ö. (2017), Sınıf Öğretmeni Adaylarının Beden Eğitimi Dersine Yönelik Tutumları. International Journal of Sport, Exercise and Training Sciences Ijsets, 3(4), 120-128. Dor: 10.18826/Useeabd.319676

Demir, G. T. ve Hazar, Z. (2018), Dijital Oyun Oynama Motivasyonu Ölçeği (DOOMÖ): Geçerlik ve Güvenirlik Çalışması. Niğde Üniversitesi Beden Ë̆itimi ve Spor Bilimleri Dergisi, 12(2).

Demir, G. T., ve Bozkurt, T. M. (2019). Dijital oyun oynama tutumu ölçeği (DOOTÖ): Geçerlik ve güvenirlik çalışması. Sportif Bakııs: Spor ve Ë̈itim Bilimleri Dergisi, 6(1), 1-18.

Demirel, H. G., Cicioğlu, H. İ., ve Demir, G. T. (2019). Lise Öğrencilerinin Dijital Oyun Oynama Motivasyonu Düzeylerinin İncelenmesi. Beden Ë̆itimi ve Spor Bilimleri Dergisi, 21(3), 128-137.

Durdu, P., Tüfekçi, A., ve Çağıltay, K. (2005), Üniversite öğrencilerinin bilgisayar oyunu oynama alışkanlıkları ve oyun tercihleri: ODTÜ ve Gazi Üniversitesi öğrencileri arasında karşılaştırmalı bir çalısma. Eurasion Journal of Educational Research, 19, 66-76.

Dursun, M., Tozoğlu, E., Bayraktar, G., Çingöz, B., ve Tozoğlu, B. (2017). Attitudes of the Students at Physical Education (PE) Teaching and Sports Department towards Technology Use in Education. International Journal of Sport Culture and Science, 5(1), 11-19. 
Mutlu Bozkurt, T., Dursun, M., \& Ar1, Ç. (2019). Spor bilimleri fakültesi öğrencilerinin dijital oyun oynamaya yönelik tutumların incelenmesi. Journal of Human Sciences, 16(4), 1217-1227. doi:10.14687/jhs.v17i1.5896

Ekinci, N. E., Üstün, U. D., ve Özer, O. (2016). An Investigation of the Relationship between Digital Game Addiction, Gender and Regular Sport Participation. Journal of education culture and Society, 6(2), 298-303.

Güvendi, B., Demir, G. T., ve Keskin, B. (2019). Ortaokul öğrencilerinde Dijital Oyun Bağımlllığ1 ve Saldırganlık. OPUS Uluslararası Toplum Arastırmalarn Dergisi, 11(18), 1-1.

Griffiths, M.D. ve Davies, M.N.O. (2005). VideogameAddiction: DoesItExist? Handbook Of Computer Game Studies. J. Goldstein, J. Raessens (Eds), Boston. MIT Pres, 359-368.

Hazar, Z., ve Demir, G. T. (2018), Sınıf Öğretmeni Adaylarının Oyun ve Fiziksel Etkinlikler Dersine Yönelik Tutum Ölçeği: Geçerlik Ve Güvenirlik Çalışması. Journal of Human Sciences, 15(2), 12061215. doi:10.14687/jhs.v15i2.5284

Hazar, Z., ve Hazar, M. (2017), Çocuklar için Dijital Oyun Bağımlllı̆̆ Ölçeği, International Journal of Human Sciences, 14 (1), 204-216.

Hazar, Z., Tekkurşun, D. G., ve Dalkıran, H. (2017). Ortaokul Öğrencilerinin Geleneksel Oyun ve Dijital Oyun Algılarının İncelenmesi: Karşılaştırmalı Metafor Çalışması. Spormetre Beden Eğitimi ve Spor Bilimleri Dergisi, 15(4), 179-190.

Huizinga, J., (2008). Homo Ludens. (ISBN 978908964003 1).

İnal, Y., ve Çağıltay, K. (2005), İlkögrretim ögrencilerinin bilgisayar oyunu oynama alşkanlıklar ve oyun terciblerini etkileyen fakttörler, Ankara Özel Tevfik Fikret Okullan, Eğitimde Yeni Yönelimler II, Eğitimde Oyun Sempozyumu, 14 Mayis, Ankara.

İnceoğlu, M. (2010). Tutum algr iletişim, Ankara: Beykent Üniversitesi Yayınevi.

Karasar, N. (2014). Bilimsel Araștrrma Yöntemi. 26. Baskı. Ankara: Nobel Akademik Yayıncılık.

Kula, A. ve Erdem, M. (2005). Öğretimsel bilgisayar oyunlarının temel aritmetik işlem becerilerinin gelissimine etkisi, Hacettepe Üniversitesi Eğitim Fakültesi Dergisi, 29: 127-136.

Lazzaro, N. (2004), Why we play games: 4 keys to more emotion. Paper presented at the Game Developer's Conference, San Jose, CA, March 22-26, 2004.

Lucas, K. ve Sherry, J. L. (2004). Sex differences in video game play: A communication-based explanation. Communication research, 31(5), 499-523.

Media Analysis Laboratory, Simon Fraser University, B.C. (1998). Video game culture: Leisure and play of B.C. teens. http://www.mediaawareness.ca/english/resources/research_documents/studies/video_games/video_game_cultu re.cfm.

Mustafaoğlu, R., ve Yasacı, Z. (2018). Dijital oyun oynamanın çocukların ruhsal ve fiziksel sağllğı üzerine olumsuz etkileri. Bağımllhk Dergisi, 19(3), 51-58.

Mustafaoğlu, R., Zirek, E., Yasacı, Z., ve Özdinçler, A. R. (2018), Dijital Teknoloji Kullanımının Çocukların Gelişimi ve Sağlı̆̆ı Üzerine Olumsuz Etkileri, Addicta: The Turkish Journal On Addictions, 5(2), 1-21.

Özdamar, K. (1999) Paket programlar ile istatistiksel veri analizi 1. Kaan Kitabevi, Eskişehir.

Pala F. K. ve Erdem, M. (2011). Dijital oyun tercihi ve oyun tercih nedeni ile Cinsiyet, sinif düzeyi ve öğrenme stili arasindaki ilişkiler üzerine bir çalişma. Abi Evran Üniversitesi Eğitim Fakültesi Dergisi, 12(2), 53-71.

Prensky, M. (2001), Digital natives, digital immigrants. From on the Horizon MCB University Press, 9(5), 1 6.

Quarser-Pohl, C., Geiser, C., ve Lehmann, W. (2006), The relationship between computergame preference, gender and mental-rotation ability. Personality and Individual Differences, 40, 609-619.

Sherry, J. L., Holmstrom, A., Binns, R., Greenberg, B.S.ve Lachlan, K. (2003). Gender and electronic game play. Submitted to Information Communication and Society. Retrieved April 8.

Squire, K. (2003), Video games in education. International Journal of Intelligent Simulations and Gaming, (2) 1.

Tabachnick, B. G. ve Fidell, L. S. (2015). Cok Değğskenli İstatistiklerin Kullanımı. (Çev: Baloğlu, M.). 6. Bask1, Ankara: Nobel Akademik Yayıncilık.

Tavşancıl, E. (2014), Tutumlarn Ölçülmesi ve SPSS İle Veri Analiz̨i (5. Baskı). Ankara: Nobel Yayınevi.

TDK. (2014). Büÿ̈k Türkse Sö̊lük. Türk Dil Kurumu. 04.11.2019 tarihinde http://www.tdk. gov.tr/index adresinden alınmıştır. 
Mutlu Bozkurt, T., Dursun, M., \& Arı, Ç. (2019). Spor bilimleri fakültesi öğrencilerinin dijital oyun oynamaya yönelik tutumların incelenmesi. Journal of Human Sciences, 16(4), 1217-1227. doi:10.14687/jhs.v17i1.5896

Topal, M., ve Aydın, F. (2018), Üniversite Ögrencilerinin Bilgisayarda Oyun Oynama Alşskanlıklar ve Bilgisayar Oyun Terciblerinin İncelenmesi: Sakarya Üniversitesi Örneği. ERPA 2018, 203.

Yengin, H. (2012). Dijital oyunlarda şiddet. Beta: İstanbul.

\section{Extended English Summary}

Technology is a feature that makes it possible to save time with its structure that makes life easier such as presenting scientific information from a virtual environment via the internet, accessing information easily and providing information to large masses. Various printed, audio, visual and written tools that provide accessibility and use of information have revealed the concept of information and communication technologies (Coşkun, 2015). Nowadays, children, adolescents and adults are experiencing with the technology, they have become involved in the virtual environment with digital devices instead of games in the street, in the park. This situation brings with it the interest of young people who are growing up and who are growing up, digital games and digital games which are expressed as digital natives (Demir \& Bozkurt, 2019). Today, young people born and raised in the age of technology and science are different in terms of play and habit, which distinguish themselves from the previous generation and are preferred as cognitive, affective and psychomotor. These differences are in line with the logic of digital games (Kula \& Erdem, 2005), which leads to a significant increase in the interest and interest in digital gaming, gaming and desire to play.Attitude can be expressed as a possible behavior which is one of the important psychological characteristics that reveal the state, attitude and behaviors of individuals and social interests (Alic1, 2013), and in other words, that the person is expected to show in the face of an event, phenomenon or situation (İnceoğlu, 2010). The reason for the existence of attitudes, the effect of attitudes on the attitudes of individuals and the fact that these attitudes cannot resist time change constantly attract the attention of the society in the age of science and technology (Demir et al., 2017). 'The attitude towards playing digital games consists of individuals' desire to clear their heads, their quest for entertainment, their desire to get away from asocial life style, their desire to escape from their environment, and their desire to apply the things they cannot reach in their lives to the digital environment (Demir \& Bozkurt, 2019). Attitudes consist of three subdimensions as cognitive, affective and psychomotor, and these sub-dimensions are in the form of an intrusive mobile cycle (Tavşancil, 2014). In this context, the information that a person exhibits in the face of a situation shows his/her mental attitude towards that situation, his/her positive attitude towards the situation shows his/her affective attitude and his/her behavior displayed shows his/her psychomotor attitude (Hazar \& Demir, 2018). At this point, the aim of this research was to determine the attitudes of the students of the Faculty of Sport Sciences towards playing digital games.

In this study made to determine the attitudes of the students of the Faculty of Sport Sciences towards playing digital games, the survey model is used, which aims to portray a phenomenon or event, which is still ongoing from past to present, as it is and in which the person or the object is tried to be described as it exists for the situation that is the subject of the study (Karasar, 2014). A total of 141 students, $66.7 \%$ of whom were male $(n=94)$ and $33.3 \%$ of female $(n=47)$, who are studying at Faculty of Sports Sciences of Gazi University participated in the study voluntarily. In order to collect data, Personal Information Form and "Playing Digital Game Attitude Scale" developed by Demir and Bozkurt (2019) were used. Before the analysis of the data obtained within the scope of the study, whether the data showed normal distribution was determined by examining the skewness and kurtosis coefficients. When the values and references are considered, it is seen that the data set is in a structure suitable for parametric tests. In this context, T-Test for Independent Samples was used for paired comparisons and One-Way ANOVA was used for comparisons with more than two groups. When variance analysis results were significant, Tukey HSD multiple comparison test was used to determine between which groups the difference occurred. Data were analyzed using SPSS 22 statistical program.

In the light of the findings obtained from the research, it was seen that there was a statistically significant difference between the attitudes of students of sports sciences faculty towards playing digital games and gender, duration of playing digital games and physical activity duration, and that there was no significant difference according to department and class variables. As a result, it was determined that the students' scores of exhibiting their digital game attitudes were moderate $(X=53.95)$. 